Available online at www.eccomasproceedia.org Eccomas Proceedia COMPDYN (2021) 1223-1241

ECCOMAS

Proceedia
COMPDYN 2021

$8^{\text {th }}$ ECCOMAS Thematic Conference on Computational Methods in Structural Dynamics and Earthquake Engineering M. Papadrakakis, M. Fragiadakis (eds.)

\title{
SELECTION OF OPTIMAL SEISMIC RETROFITTING FOR EXISTING SCHOOL BUILDINGS THROUGH MULTI-CRITERIA DECISION MAKING
}

\author{
Wilson W. Carofilis ${ }^{1}$, Nicholas Clemett ${ }^{1}$, Giammaria Gabbianelli ${ }^{1}$, Gerard O'Reilly ${ }^{1}$, \\ and Ricardo Monteiro ${ }^{1}$ \\ ${ }^{1}$ Centre for Training and Research on Reduction of Seismic Risk (ROSE), Scuola Universitaria \\ Superiore IUSS Pavia
}

Palazzo del Broletto, Piazza della Vittoria 15, Pavia 27100, Italy

e-mail: \{wilson.carofilis,nicholas.clemett,giammaria.gabbianelli,gerard.oreilly, ricardo.monteiro\}@iusspavia.it

\begin{abstract}
The poor performance of school buildings in Italy during past seismic events has underlined their high vulnerability to earthquakes. To improve their seismic performance, retrofitting interventions are commonly designed and then evaluated against a range of key decision criteria. However, more than one intervention may be found to reduce the seismic risk of the structure but it may not be clear which scheme is the most effective given the diverse evaluation criteria. In such cases, multi-criteria decision-making procedures are practical tools that can help to solve this issue, especially when multiple evaluation parameters are considered. This study conducts a full seismic assessment of two existing $R C$ school buildings located in different regions of Italy. For both buildings, similar retrofitting interventions are proposed and designed according to the requirements specified by the Italian building code, NTC 2018. The retrofitting interventions are assessed through non-linear dynamic analyses to thoroughly estimate their overall performance and expected losses. The retrofitting interventions are then comparatively evaluated considering parameters that integrate economic, social, environmental and technical aspects that have a significant role in the decision-making process. The preferential rankings of the retrofit alternatives obtained for both buildings are used to identify the optimal retrofitting solutions for each case and are compared to determine what parameters influence such optimal solutions according to the different buildings' characteristics. The outcomes of this study can assist engineers, or general decision-makers, throughout the evaluation and subsequent selection of retrofit ptions for existing school buildings.
\end{abstract}

Keywords: RC school buildings, MCDM, retrofitting interventions, NTC 2018, evaluation parameters. 


\section{INTRODUCTION}

The seismic risk of existing school buildings is an important topic that has been addressed in recent years. For instance, Perrone et al. [1] conducted an extensive performance assessment for three school building typologies adapted from the Progetto Scuole developed by the European Centre for Training and Research in Earthquake Engineering (EUCENTRE). Building upon such work, Carofilis et al. [2] proposed and assessed different retrofitting techniques to reduce the seismic risk of the same school buildings. Besides evaluating the seismic performance, Carofilis et al. [2] determined the economic feasibility of these alternatives through a cost-benefit analysis [3]. However, as further explored by Carofilis et al. [4], the consideration of a diverse set of decision variables (DV) for a set of retrofitting strategies may result in a distinct retrofitting preference, when compared to traditional economic assessments. Therefore, Carofilis et al. [4] suggested that multi-criteria decision making (MCDM) analysis is more suitable than other methodologies, which tends to focus only a few decision variables, for selecting the most advantageous option from a set of retrofitting strategies. Similarly, MCDM has been adopted in other studies focusing on the retrofitting alternatives for residential buildings (Caterino et al. [5]) and school buildings (Gentile and Galasso [6]), where technical, social, and economic aspects were evaluated.

With the current focus on reducing impact that humans have on the environment, a body of recent research has also focused on assessing the environmental impacts associated with the seismic damage of existing buildings. Recently, Caruso et al. [7] proposed a methodology for considering the life cycle costs and environmental impacts (EIs) associated with the seismic and energy efficiency retrofitting of existing buildings. Additionally, Caruso et al. [7] investigated how this methodology could be used for the selection of retrofitting alternatives.

Subsequently, Clemett et al. [8] carried out a detailed and comprehensive review of five different metrics that can be used to account for the EI of retrofitting strategies within an MCDM framework. They found that incorporating the EI into the MCDM analysis influenced the identification of the ideal retrofitting solution, as the selection of an appropriate EI DV affected the preference ranking of the retrofitting solutions. Therefore, in the selection of the most convenient retrofitting strategy for an existing school building not only traditional aspects (i.e. technical, economic and social views), but also environmental impacts should be considered. With the above aspects in mind, this paper looks at the retrofitting of two case study existing buildings in Italy, where several retrofitting alternatives are examined and the choice via an MCDM framework, considering economic, social, environmental and technical aspects, is carried out.

\section{MULTI-CRITERIA DECISION MAKING (MCDM)}

The MCDM framework is advantageous when considering a number of different DVs, complemented by an analytical hierarchy process (AHP) [9]. Additionally, the "technique for order preference by similarity to ideal solution" (TOPSIS) [10] can be applied to rank the assessed options according to their relative closeness to an ideal alternative, which comprises all of the most convenient characteristics (e.g. best performance, lowest cost, lowest losses, etc.). Nevertheless, the closeness to an ideal solution depends on the importance given to each DV by the analyst, as well as to their specific values.

\subsection{Description of the method}

At the start of an MCDM analysis, it is necessary to define the evaluation parameters or DVs. Then, the importance given to each DV is assigned. This importance is represented 
through a weight vector (w), which can be defined according to a preference matrix as implemented by Caterino et al. [5] or through a survey, as performed by Carofilis et al. [11] and Gentile and Galasso [6]. The values of each retrofitting alternative associated with each DV create the decision matrix (D), which along with the weight vector (w) represent the input variables. Figure 1 summarizes the process to develop the MCDM analysis. The decision matrix is normalized since each DV may be expressed in different units. The normalized decision matrix $\mathrm{R}$ is determined by applying Equation 1 to the elements of the decision matrix (D). Then, the weight normalized decision matrix $\mathrm{V}$ is calculated through Equation 2, where $\mathrm{r}_{\mathrm{ij}}$ represents the components of matrix $\mathrm{R}$ and $\mathrm{w}_{\mathrm{j}}$ the elements of the weight vector $(\mathrm{w})$. From the matrix $\mathrm{V}$ the most ideal solution $\mathrm{A}^{*}$ and negative-ideal solution $\mathrm{A}$ - are determined, representing the most and least convenient values for each column of matrix $\mathrm{V}$. These parameters are used to calculate the distances $\mathrm{Si}^{*}$ and $\mathrm{Si}-$ as indicated by Equation 3. As illustrated in Figure 1, these distances represent the proximity of each alternative to a fictitious ideal and negative-ideal alternative. Finally, the relative closeness (Equation 4) is used to rank the alternatives and determine the most convenient one, i.e. the alternative with the largest relative closeness. For example, in Figure 1, it is observed that A2 is closer to the ideal fictitious alternative in comparison with $\mathrm{A} 1$ and A3. Consequently, A2 will be assumed the most favourable alternative since its relative closeness would be much larger than that of the other alternatives. Further details of this method can be found in [5] and $[4,11]$.

INPUT VARIABLES

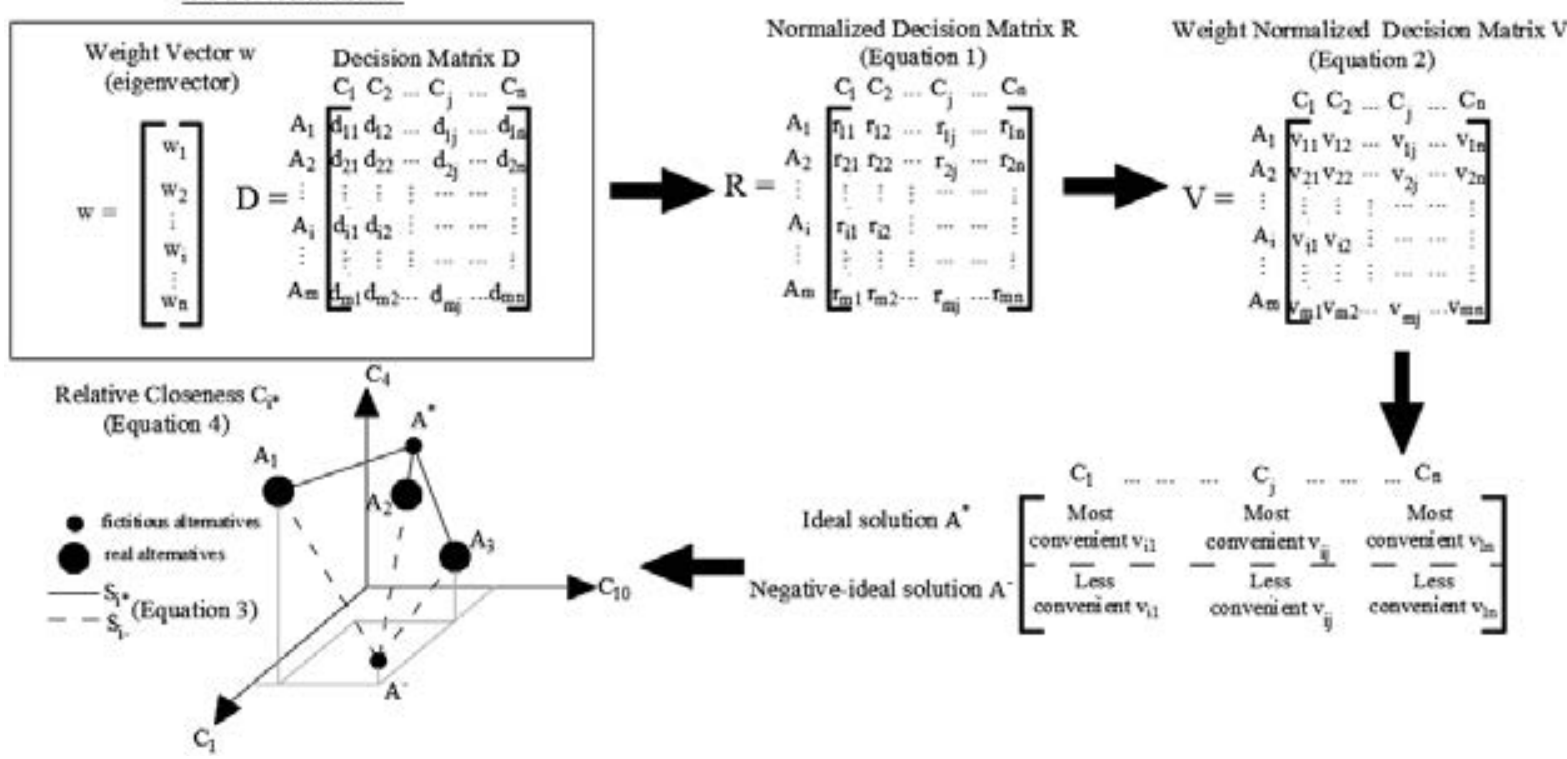

Figure 1: MCDM procedure.

$$
\begin{gathered}
r_{i j}=\frac{\boldsymbol{d}_{i j}}{\sqrt{\sum_{\boldsymbol{k}=\mathbf{1}}^{m} \boldsymbol{d}_{\boldsymbol{k} j}{ }^{2}}} \\
v_{i j}=r_{i j}{ }^{*} w_{j} \\
S_{i *}=\sqrt{\sum_{j=1}^{n}\left(v_{i j}-v_{j *}\right)^{2}} ; \quad S_{i-}=\sqrt{\sum_{j=1}^{n}\left(v_{i j}-v_{j-}\right)^{2}} \text { (Distances } \mathrm{S}_{\left.\mathrm{i} * \text { and } \mathrm{S}_{\mathrm{i}-}\right)}
\end{gathered}
$$




$$
C_{i *}=\frac{s_{i-}}{s_{i *}+s_{i-}} C_{i *}=\frac{s_{i-}}{s_{i *}+s_{i-}}(\text { Relative closeness })
$$

\subsection{Evaluation parameters}

The DVs selected for this study were in part characterised through an ad-hoc survey devised by Carofilis et al. [11], which collected information on which evaluation parameters are considered important in the assessment of retrofitting options for school buildings. These variables are reported in Table 1, where it is indicated to which aspect they are related and how they are estimated for each retrofitting configuration. Some of these variables have also been investigated in past studies $[5,6]$.

\begin{tabular}{|c|c|c|c|}
\hline Label & $\begin{array}{l}\text { Decision } \\
\text { Variable }\end{array}$ & Aspect & How this DV is determined \\
\hline $\mathrm{C} 1$ & Installation Costs & Economic & $\begin{array}{l}\text { Total cost of installation comprising removal, } \\
\text { demolition, application of retrofitting technique and all } \\
\text { other cost associated with applying the intervention }\end{array}$ \\
\hline $\mathrm{C} 2$ & $\begin{array}{l}\text { Maintenance } \\
\text { Costs }\end{array}$ & Economic & Cost of maintenance over the lifetime of the structure. \\
\hline $\mathrm{C} 3$ & $\begin{array}{l}\text { Duration of } \\
\text { Works }\end{array}$ & $\begin{array}{l}\text { Economic/ } \\
\text { Technical }\end{array}$ & $\begin{array}{l}\text { Number of days needed to fully complete the } \\
\text { intervention and start the normal operation of the } \\
\text { building }\end{array}$ \\
\hline $\mathrm{C} 4$ & $\begin{array}{l}\text { Architectural } \\
\text { Impact }\end{array}$ & Social & Qualitative evaluated through AHP [9] \\
\hline $\mathrm{C} 5$ & $\begin{array}{l}\text { Need for } \\
\text { Specialized Labor }\end{array}$ & Technical & Qualitative evaluated through AHP [9] \\
\hline C6 & $\begin{array}{l}\text { Foundation } \\
\text { Intervention }\end{array}$ & Technical & $\begin{array}{l}\text { Estimates of the maximum axial load ratio between the } \\
\text { retrofitting intervention to the as-built configuration }\end{array}$ \\
\hline $\mathrm{C} 7$ & $\begin{array}{l}\text { Expected Annual } \\
\text { Losses }\end{array}$ & Technical & $\begin{array}{l}\text { Evaluated as the expected annual loss obtained from } \\
\text { the loss assessment using PACT [12]. }\end{array}$ \\
\hline $\mathrm{C} 8$ & $\begin{array}{l}\text { Expected Annual } \\
\text { EI }\end{array}$ & $\begin{array}{l}\text { Technical/ } \\
\text { Social }\end{array}$ & Refer to Section 2.3 \\
\hline
\end{tabular}

Table 1: Evaluation parameters.

\subsection{Environmental impact}

Clemett et al. [8] highlighted how an EI metric that captures the entire life cycle impacts can be incorporated into the MCDM. The EI of a building can be estimated in several ways. For instance, through a Process Life Cycle Assessment (PLCA) inventory, containing a list of all the processes that contribute to the life cycle of a building. PLCA is generally considered a meticulous approach for estimating the life cycle EI of a structure, however, it is particularly time-consuming to develop a full inventory accounting for all sources of EI. Therefore, PLCA is susceptible to truncation bias (i.e. 30-50\% of the total life cycle impacts [13]). An alternative to PLCA is the Environmentally Extended Input-Output Life Cycle Assessment (EEIOLCA), which, unlike PLCA, is a top-down method based on economic input-output (IO) models [14]. These IO models capture the monetary transactions that occur between the different sectors of the economy and are generally represented as matrices [15] (Figure 2, point 3). If rows and columns are included for the various EI metrics of interest, these tables can be used to assess 
the EI of each industrial sector. The values for each impact category are generally presented in EIs/\$ [16]. The EI of a building can be calculated by disaggregating the total cost estimate of the structure into each of the available industrial sectors and then multiplying the dollars spent in each sector by sector- unique EI/\$ value.

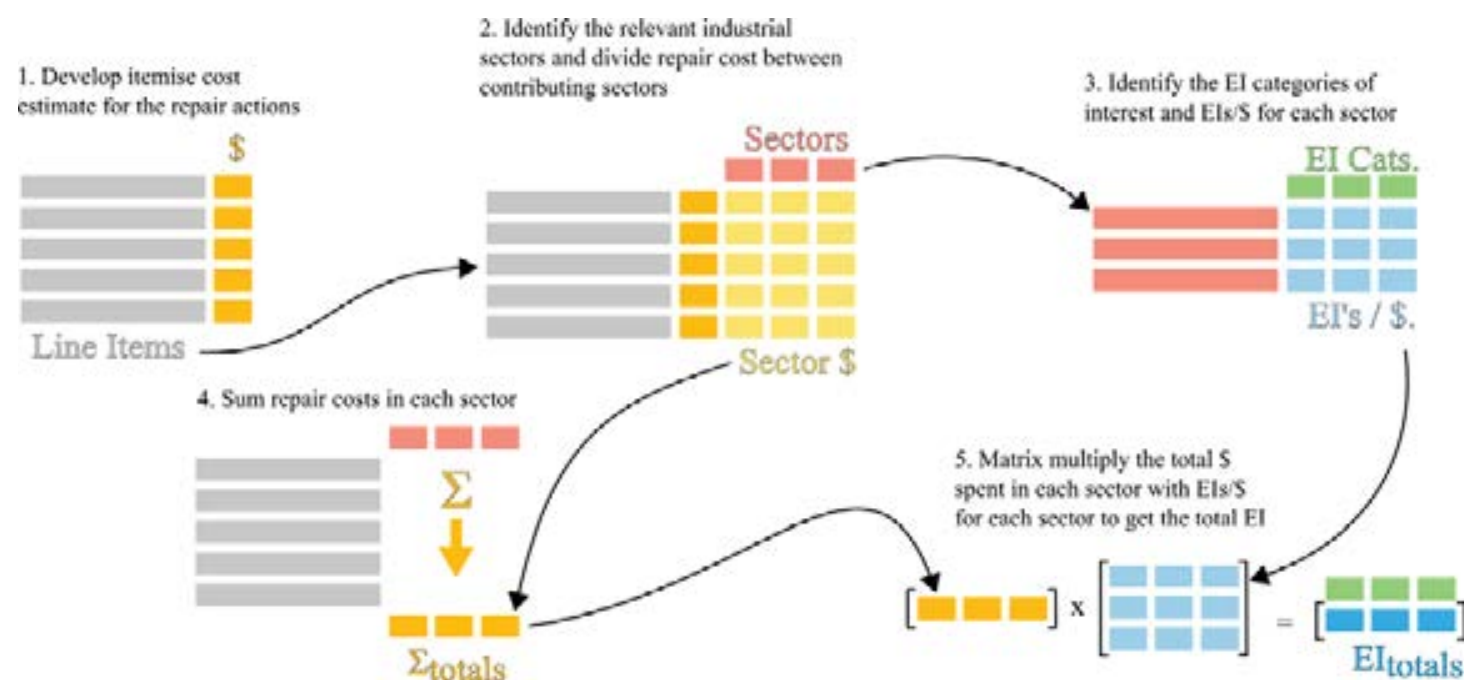

Figure 2: EEIOLCA impact assessment procedure adapted from Huang and Simonen [16].

Nevertheless, it is important to note that EEIOLCA has three primary sources of error: aggregation error (i.e. values represent a weighted average of several smaller economic sectors); the homogeneity assumption (i.e. all products produced within a specific sector have the same average EI), and; the linearity assumption (i.e. EIs are linearly correlated with the market price, meaning that a higher price leads to higher emissions) [8]. Additionally, EEIOLCA might present other limitations and potential sources of uncertainty. For example, the USEEIO [17] inventory has been developed using US economic data so that EIs derived from its use are applicable only within the United States. The application of this inventory to case studies outside of the US will likely increase the error of the impact estimate unless it can be demonstrated that the economy of interest has the same structure as the US economy. In this study, the use of the USEEIO inventory for a case-study building in Italy can be justified by the fact that the assessments performed are for comparative purposes and any error resulting from the use of a US inventory will likely have an equal effect on all of the retrofitted structures. Additionally, the USEEIO database [17] does not consider any sort of uncertainty in the EI estimates for each sector, however, uncertainty in these values is accounted for in the PACT software (version 3.1.2) [12] by assuming that the uncertainty of the EIs is related to the uncertainty of the cost estimate (refer to Equation 1 of Clemett et al. [8]).

For this study, the EI, denoted C8, was estimated using EEIOLCA which represents the ongoing cost associated with the retrofit alternatives, and is impacted by the seismic performance (i.e. the effectiveness) of the retrofit alternatives [8]. The reconstruction EI was coarsely approximated by first converting the reconstruction cost, in $2020 €$ to $2013 \$$, then multiplying the reconstruction cost by the EIs/€ factor for "schools and vocational buildings" from the USEEIO database [17]. An additional 15\% of the reconstruction EI was added to 
account for the impacts associated with the demolition and disposal of the damaged structure [8].

\section{CASE-STUDY BUILDINGS}

Two existing reinforced concrete (RC) school buildings located in different regions of Italy with medium-high seismicity are used as case-study. These structures share the same modelling techniques (Figure 3a), as well as structural deficiencies. The first building is referred to as Building 1 (Figure 3b) and is located in central Italy, at Isola del Gran Sasso, Parozzani. This school building consists of two storeys and one underground portion (staircase section), the construction period is estimated at around 1960-1970. The area of the underground level is $133 \mathrm{~m}^{2}$ and for the subsequent levels is $631 \mathrm{~m}^{2}$. Likewise, the inter-storey heights are $3.75,3.75$ and $4.75 \mathrm{~m}$, respectively for each level. The second building is denoted as Building 2 (Figure $3 b$ ) and is located on Italy's Adriatic coast, in Ancona. It is estimated that the construction period of this building dated back to the $60 \mathrm{~s}$. The structure is composed of three storeys including an underground level. The floor area is about $690 \mathrm{~m}^{2}$, and inter-storey height of $3.83 \mathrm{~m}$ for the underground level and first storey, and $3.77 \mathrm{~m}$ for the second storey.

\subsection{Structural modelling}

These buildings share similarities in their configuration, size, material and year of construction. Therefore, the same assumptions were adopted for the numerical modelling of both buildings with the software OpenSees [18] as illustrated in Figure 3. The modelling techniques suggested by O'Reilly and Sullivan [19] for old RC Italian frames were implemented. For example, beams and columns were created through force-based beamcolumn elements with a modified Radau plastic hinge integration scheme with lumped plasticity (Scott and Fenves [20]). Even though the shear behaviour was assumed elastic, a postprocessing analysis was carried out to compare the shear forces of these flexural elements to their maximum shear capacity determined through NTC -2018 [21]. On the other hand, the beam-column joints were modelled using a zero-length rotational spring to capture any potential shear failure for joints. Furthermore, the buildings also incorporate a rigid floor slab and consider second-order geometry effects (P- $\Delta)$. Regarding damping, a 5\% tangent-stiffnessproportional Rayleigh damping model for the periods of the fundamental modes was adopted. Additionally, the effects of the exterior masonry infills were incorporated into the model through a system of equivalent diagonal struts that represent the behaviour of the infills, following the recommendations of Sassun et al. [22]. To account for the influence of openings, the stiffness and strength of the struts were affected by a reduction factor proposed by Decanini et al. [23]. The strut models used in these analyses are only capable of modelling the in-plane behaviour of the infills and do not consider out-of-plane failure. Further details about the building configuration and modelling can be found in [8] and [1,2] for Building 1 and 2, respectively. 
Flexural Elements

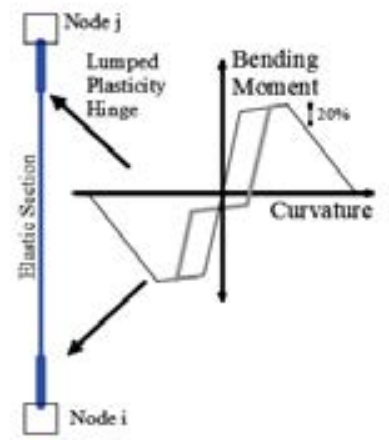

Beam-column Joints

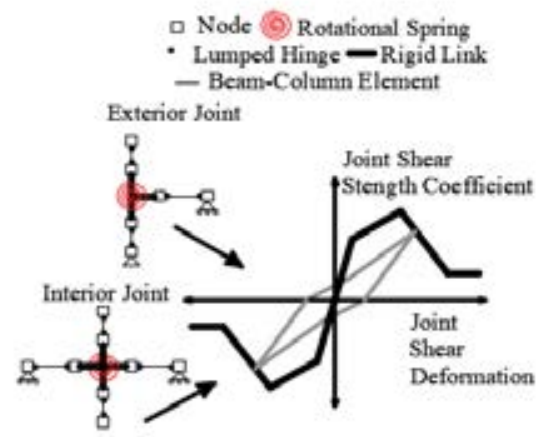

Masonry Infiils

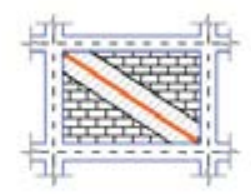

Equivalent Diagonal fStrut Force

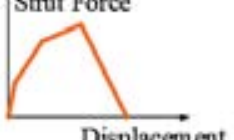

(a) Adopted modelling techniques

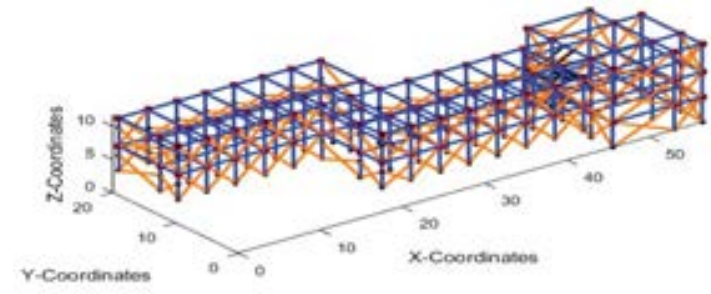

Longitudinal Elevation
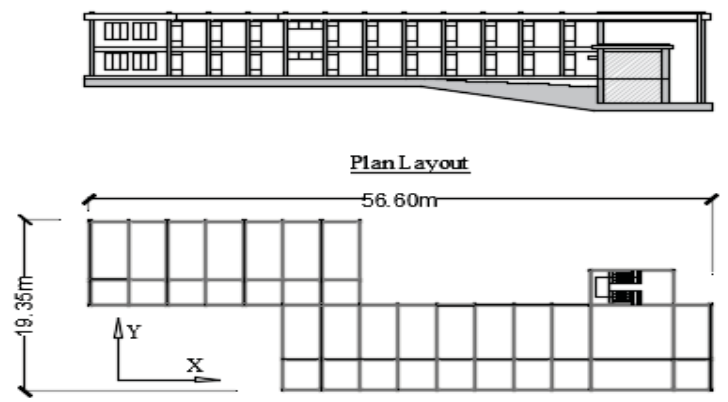

Building 1

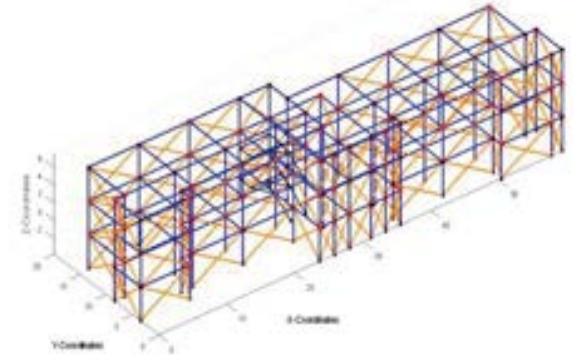

Longitudinal Elevation

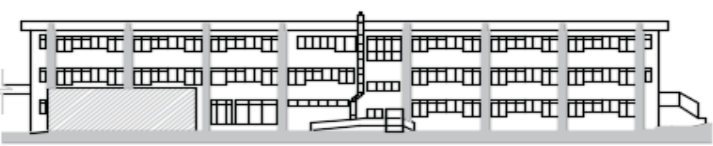

$\underline{\text { Plan Layout }}$

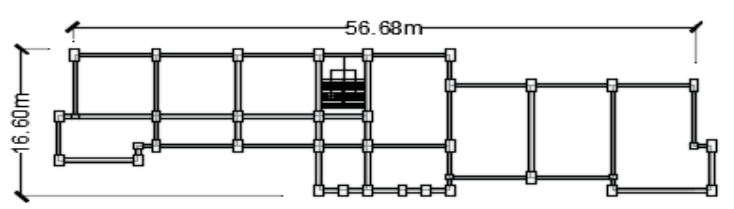

Building 2

(b) Buildings configuration

Figure 3: Schemes of case-study school buildings.

\subsection{Performance assessment}

A performance assessment was developed for both buildings, carrying out verifications of deformation and strength capacity for the seismic demands imposed by NTC 2018 [21] according to the site location of each building. For a school building, the NTC 2018 [21] specifies a design life of 75 years (occupancy class III) and return periods associated with four limit states: Operational limit state (SLO) 45 years; Damage limitation limit state (SLD) 75 years; Life safety limit state (SLV) 712 years, and; Collapse prevention limit state (SLC) 1463 years. For the serviceability limit states, the code imposes two drift limits $0.17 \%$ and $0.5 \%$ for SLO and SLD, respectively. For a building of occupancy class III, it is only necessary to verify the limit at SLO, however, in this study, both limits were checked.

The results of the preliminary performance assessment are illustrated in Figure 4. They are expressed in terms of the base shear coefficient (i.e. lateral capacity divided by the seismic weight of the building), building roof drift (i.e. roof displacement divided by the total height of the building) and drift profiles related to the different limit states. On the one hand, it is observed 
that the capacity of both buildings is controlled by the premature failure of joints, and thereby controlling the other limit states as well. In the case of the drift profile, Building 1 meets the drift limit for both serviceability limit states in both directions. On the other hand, Building 2 exceeds these limits, especially for the Y direction. For the limit states associated with the ultimate capacity (i.e. SLV and SLC), both buildings present a soft-storey mechanism which is denoted by the drift concentration in one of their storeys, namely second storey for Building 1 and third storey for Building 2.

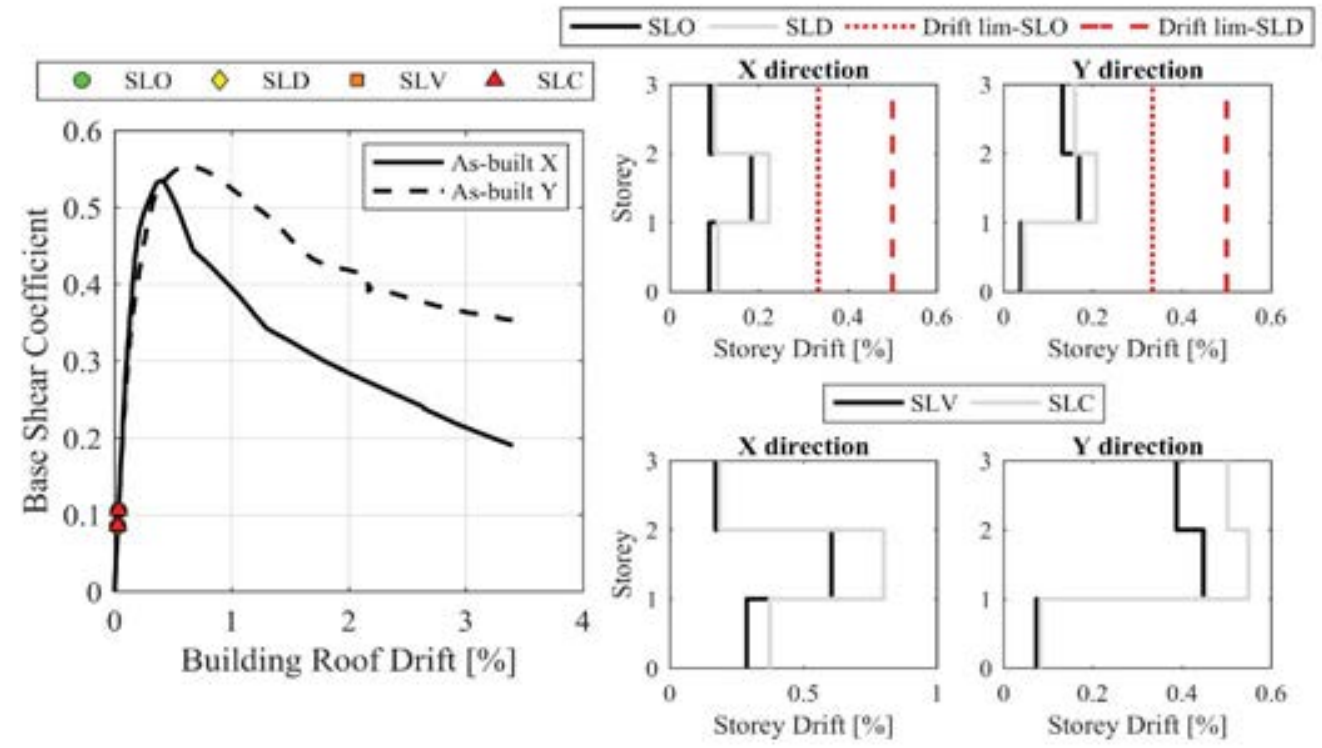

(a) Building 1

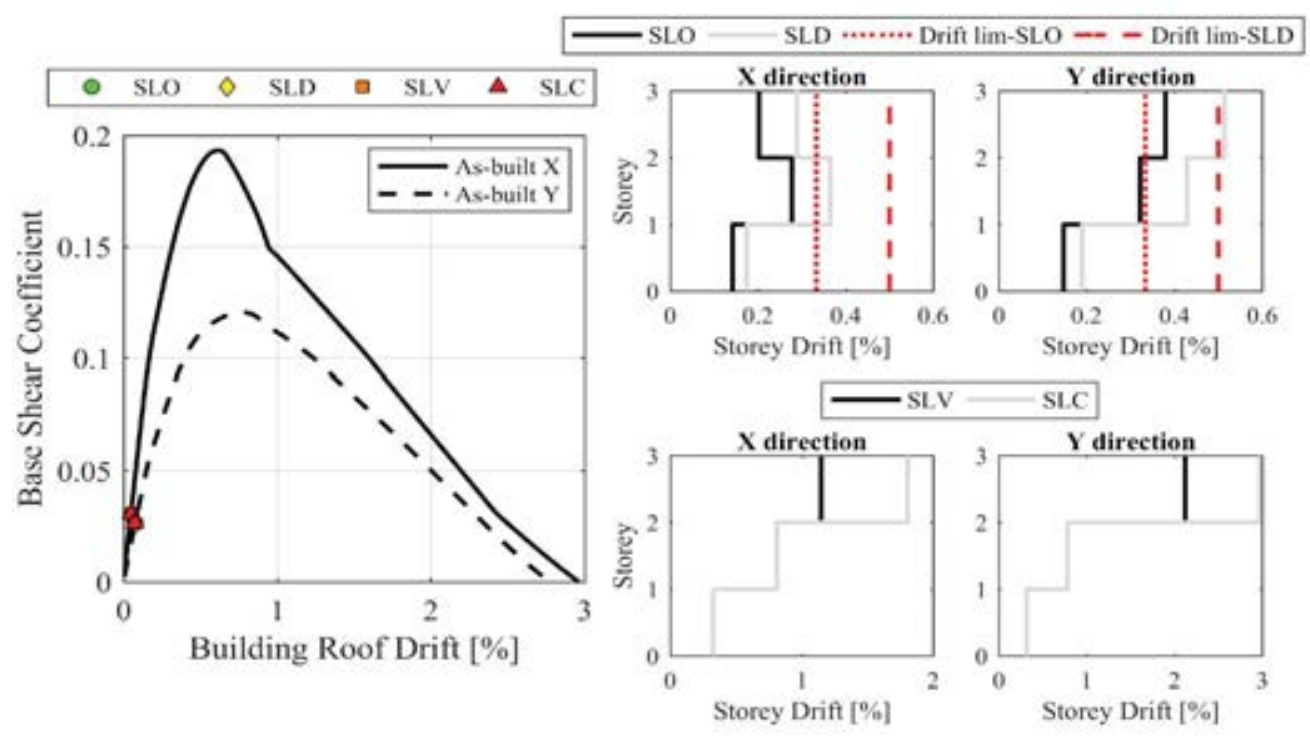

(b) Building 2

Figure 4: School buildings structural performance.

\section{RETROFITTING INTERVENTIONS}

Four retrofitting strategies were proposed for both school buildings. As illustrated in Figure 5, these strategies are the same for both buildings and consist of: A1 involves carbon fiber reinforced polymer (CFRP) wrapping of columns along with CFRP bars, as well as CFRP strips placed on beam-column joints; A2 implements exterior cross-steel braces in some strategic locations of the building; A3 combines the two previous interventions (i.e. CFRP and steel 
braces) and, lastly; A4 combines CFRP and viscous dampers placed strategically in the building. Moreover, the infill-strut elements were removed from the models in response to the seismic separation of the infills and the frames. To accommodate this assumption, additional checks were carried out during the non-linear analyses to ensure that the estimated drifts did not exceed the $50 \mathrm{~mm}$ seismic gap provided. Further details of the original and retrofitted configurations, as well as their design, can be found in $[4,8]$.

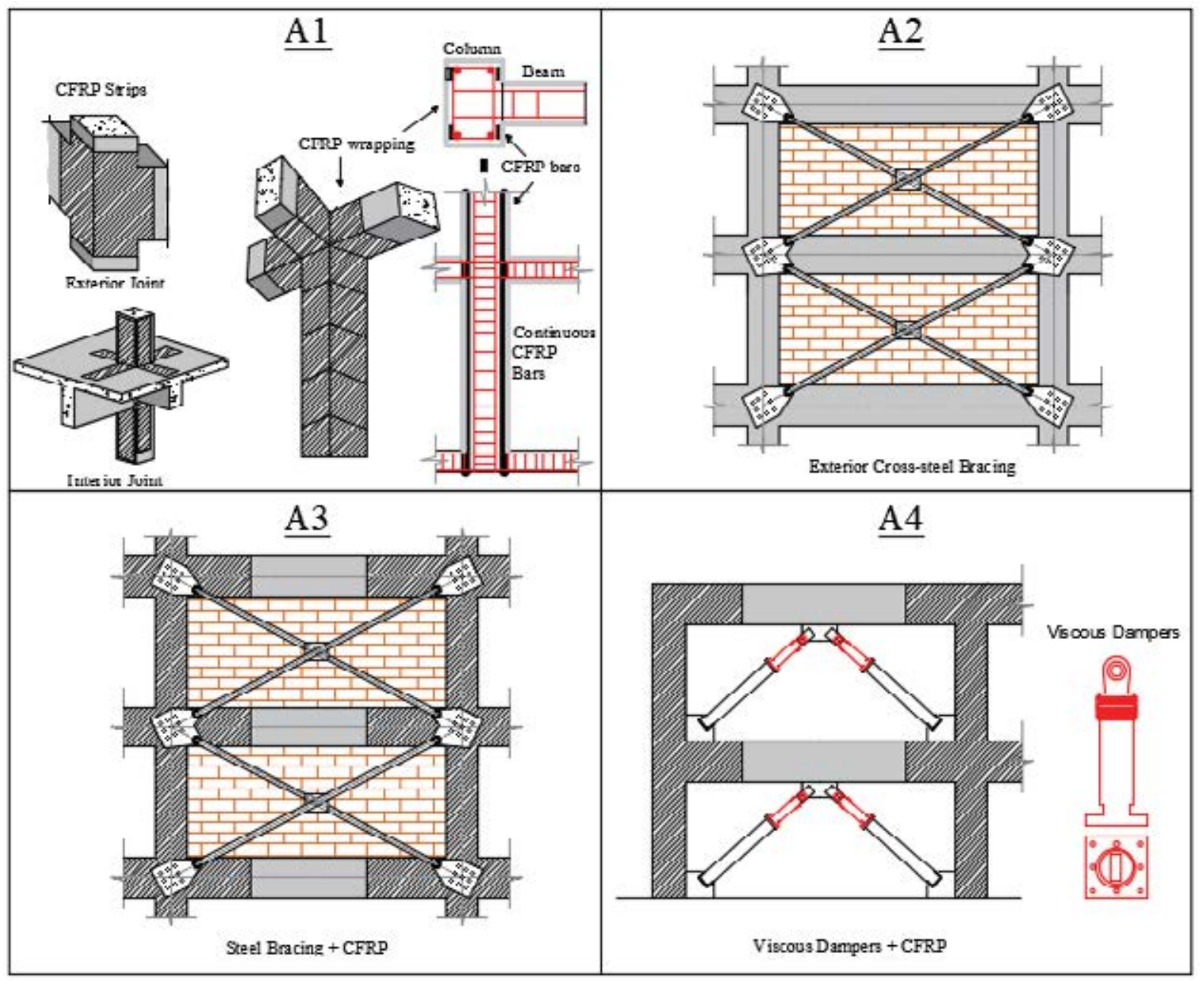

Figure 5: Proposed retrofitting configurations.

\subsection{Performance assessment of retrofitting strategies}

The performance assessment was applied to the retrofitting configuration, again this assessment is reported as drift profiles (Figure 6) and lateral capacity (Figure 7). For Building 1 all retrofitting interventions meet the drift limit for SLO and SLD whereas they reduce the drift concentration for SLV and SLC. In the case of Building 2, all strategies improve the drift distribution, especially for the Y direction. However, strategy A1 is slightly exceeding the drift limit at SLO and at SLD the maximum storey drift coincides with the drift limit.

The strategies involving steel braces (A2 and A3) prove to be more effective in reducing the storey drift in both building configurations. The strategy with viscous dampers (A4) reduces the drift concentration, and the option with CFRP (A1) also reduces the drift profiles but its effect is not as substantial as the other strategies.

Moreover, the lateral capacity, as well as performance capacity points, are improved for all strategies except for A2 (steel braces). Even though this strategy boosts considerably the lateral 
capacity of the buildings, in terms of local strength does not account for an improvement since the strength capacity remains unchanged and thereby the premature failure of joints still persists. Strategy A3 also boosts the lateral capacity of the buildings, the action of the CFRP increases the local capacity of the structural elements so that the capacity points are shifted to the right (i.e. a zone of better performance). The same effect is observed for A1 and A4, which also incorporate CFRP. Furthermore, a particular difference of the steel bracing options (A2 and A3) is noted in the lateral capacity of the case-study buildings (Figure 7a). The contribution of the bare frame (due to seismic separation of infills) and steel braces present a lower initial stiffness than that of the as-built configuration for Building 1. On the other hand, in Building 2, this same combination results in a stiffer building, meaning that the steel bracing system surpasses the stiffness of the infilled configuration (as-built).
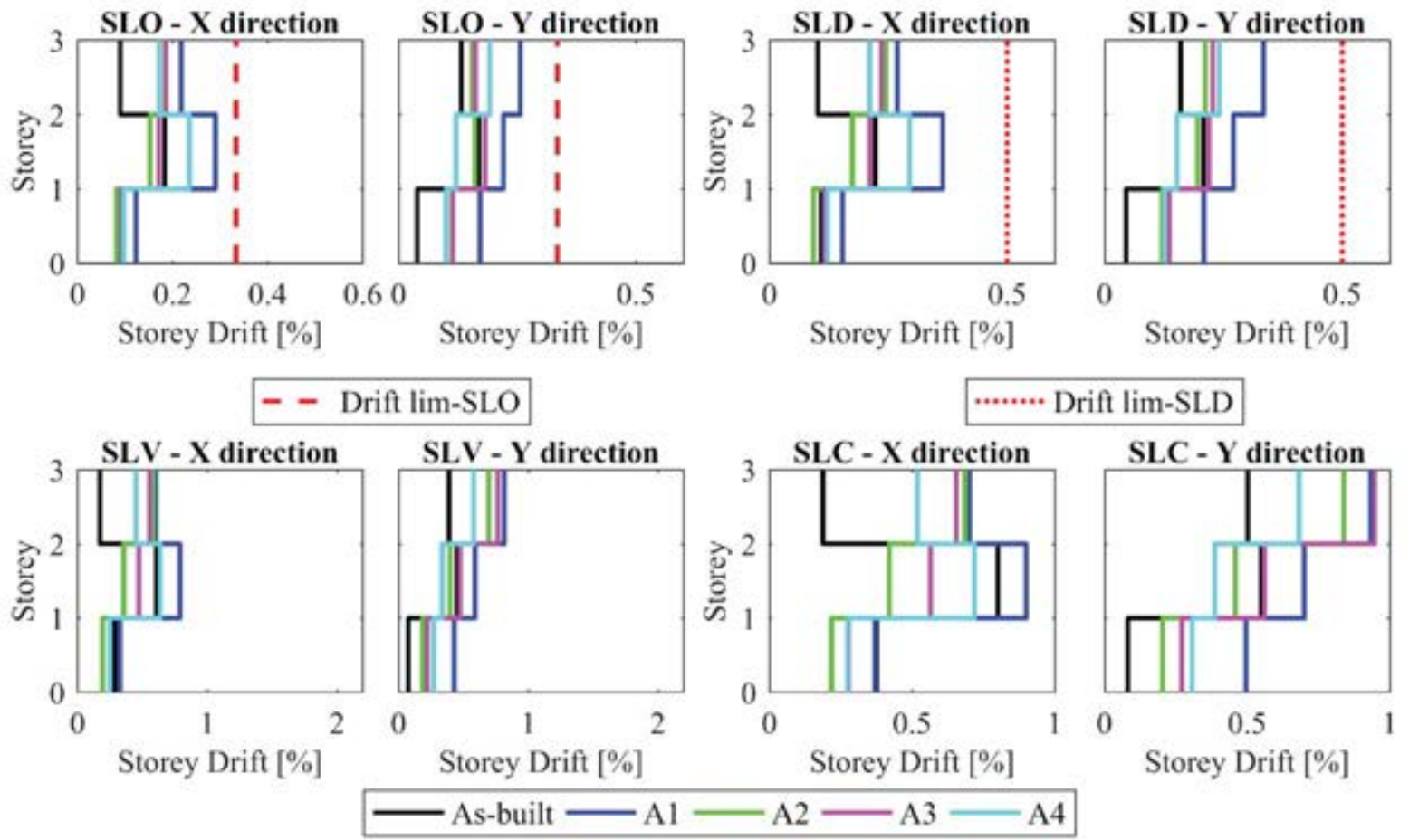

(a) Building 1 

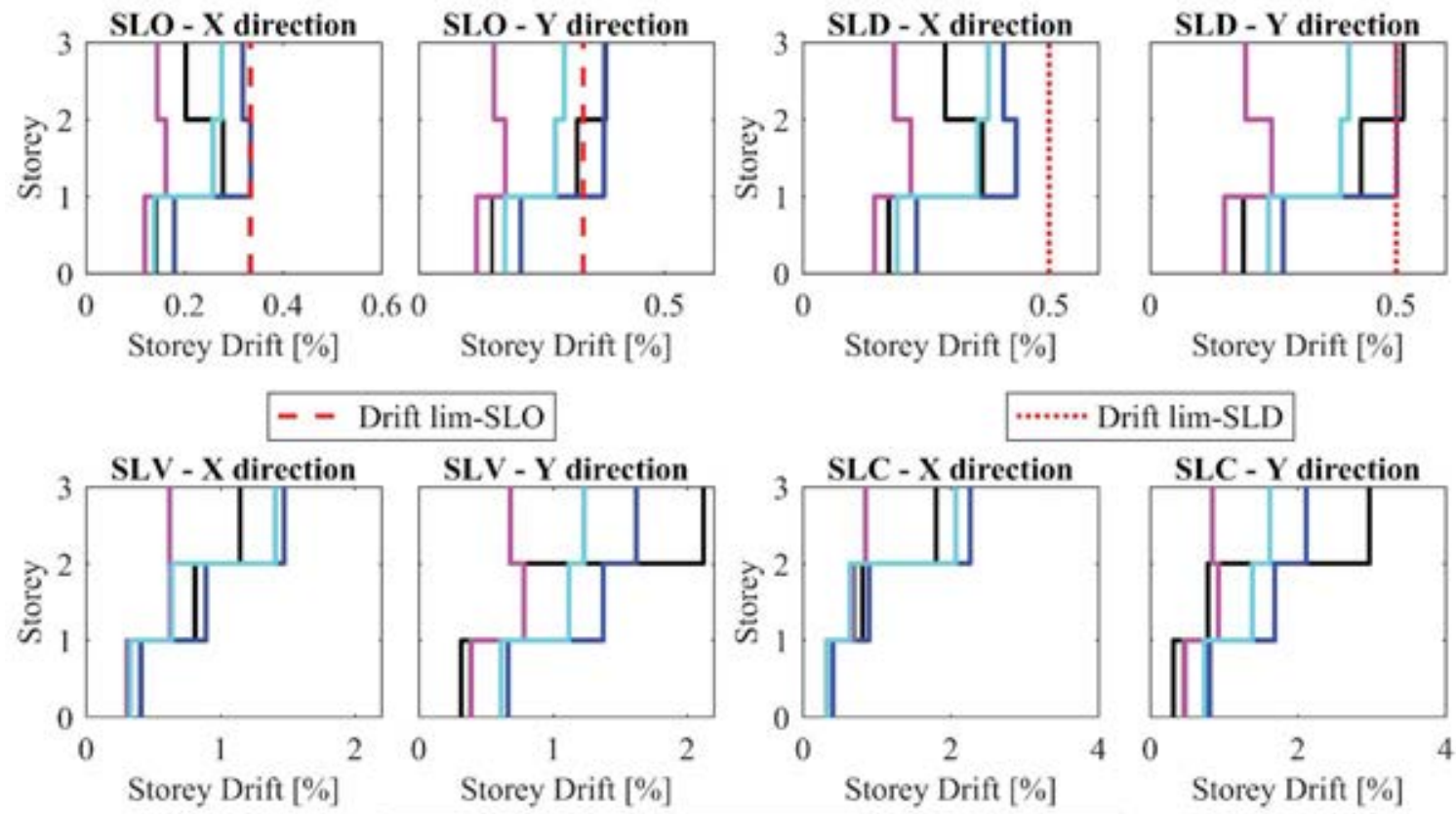

$\longrightarrow$ As-built $\longrightarrow$ A1 $-\mathrm{A} 2-\mathrm{A} 3-\mathrm{A} 4$

(b) Building 2

Figure 6: Drift profiles of retrofitting interventions.
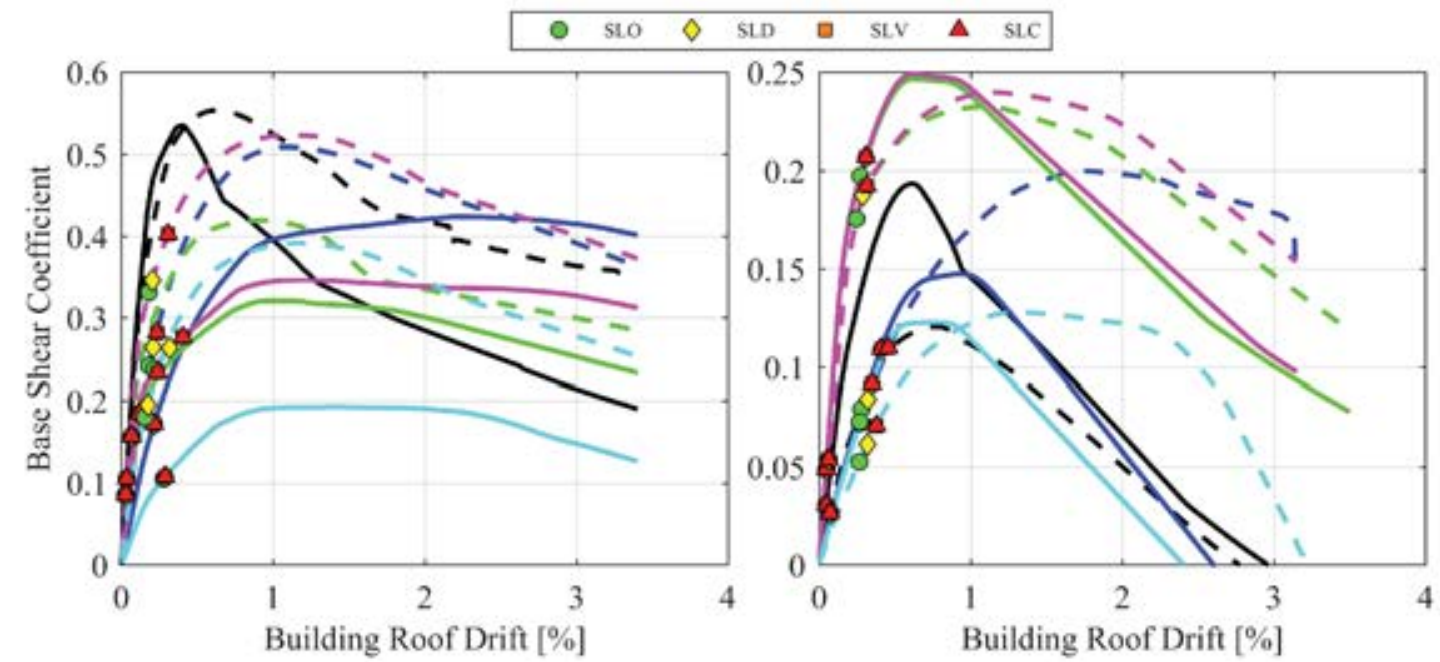

- As-built X - - As-buitt Y

(a) Building 1

(b) Building 2

Figure 7: Lateral capacity of retrofitting interventions.

\subsection{Collapse vulnerability and loss estimation}

The next stage in the performance assessment was to conduct refined nonlinear time history analysis (NLHA). Therefore, the fundamentals periods of all models were determined (they are reported in Table 2 and Table 1 for Building 1 and 2, respectively). Due to the period variability of the different models, the average spectral acceleration (AvgSa) was considered as intensity measure to carry out a ground motion record selection, since it is a more efficient and unbiased quantifier of response in these structural typologies, as shown by O'Reilly [24]. The software 
OpenQuake [25] was used to carry out the probabilistic seismic hazard analysis (PSHA) and disaggregation analyses for the site locations defined in Section 3. The Italian seismic source model MPSO4 (Meletti et al. [26]) and the ground motion model by Akkar, Sandikkaya, and Bommer [27] and Sandikkaya, Akkar, and Bard [28] were adopted. The geometrical period (Tgm) was determined as the square root of the product between the two fundamental periods. The period range of $0.2 \mathrm{Tg}-1.5 \mathrm{Tg}$ was used to perform the AvgSa-based selection, as suggested by Kohrangi et al. [29]. The period range of $0.05 \mathrm{~s}$ to $1.0 \mathrm{~s}$ was adopted for Building 1 whereas a range of $0.10 \mathrm{~s}$ to $1.60 \mathrm{~s}$ was used for Building 2. A set of 20 pairs of ground motion records in two horizontal components were selected for ten return periods: 30, 45, 75, 100, 200, 475, $712,975,1463$ and 2475 years. Figure 8 illustrates the hazard curves for the two sites locations, expressed in terms of the mean annual frequency of exceedance (MAFE) and AvgSa, as well as a scheme of the ground motion selection at a specified intensity.

\begin{tabular}{cccccc}
\hline Model & $\mathrm{Tx}[2]$ & $\mathrm{Ty}[\mathrm{s}]$ & $\mathrm{Tg}[\mathrm{s}]$ & $0.2 \mathrm{Tg}[\mathrm{s}]$ & $1.5 \mathrm{Tg}[\mathrm{s}]$ \\
\hline As-built & 0.27 & 0.24 & 0.25 & 0.04 & 0.38 \\
A1 & 0.60 & 0.37 & 0.47 & 0.09 & 0.71 \\
A2 & 0.41 & 0.37 & 0.39 & 0.07 & 0.58 \\
A3 & 0.40 & 0.35 & 0.37 & 0.08 & 0.56 \\
A4 & 0.75 & 0.35 & 0.51 & 0.10 & 0.77 \\
\hline
\end{tabular}

Table 2: Fundamental periods, geometric period, and period range for the models of Building 1.

\begin{tabular}{cccccc}
\hline Model & $\operatorname{Tx}[2]$ & $\mathrm{Ty}[\mathrm{s}]$ & $\mathrm{Tg}[\mathrm{s}]$ & $0.2 \mathrm{Tg}[\mathrm{s}]$ & $1.5 \mathrm{Tg}[\mathrm{s}]$ \\
\hline As-built & 0.57 & 0.80 & 0.68 & 0.14 & 1.01 \\
A1 & 0.98 & 1.00 & 0.99 & 0.20 & 1.49 \\
A2 & 0.53 & 0.59 & 0.56 & 0.11 & 0.84 \\
A3 & 0.53 & 0.59 & 0.56 & 0.11 & 0.84 \\
A4 & 0.98 & 1.17 & 1.07 & 0.21 & 1.61 \\
\hline
\end{tabular}

Table 3: Fundamental periods, geometric period, and period range for the models of Building 2.

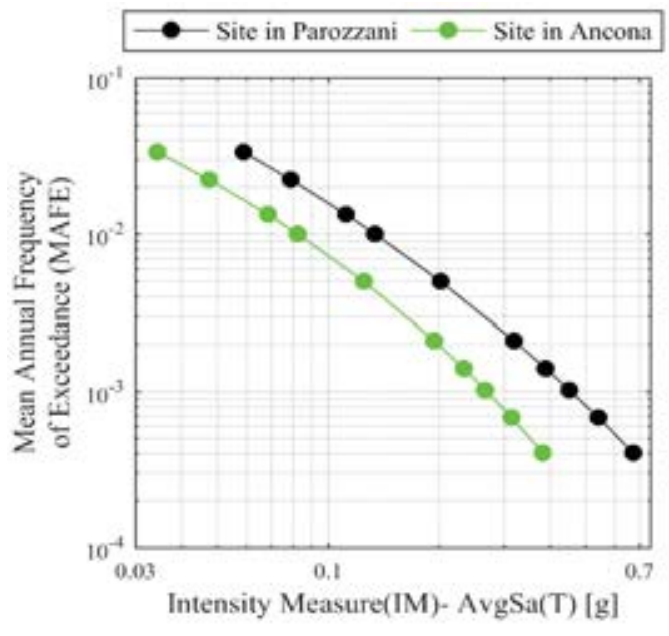

(a) Hazard curves

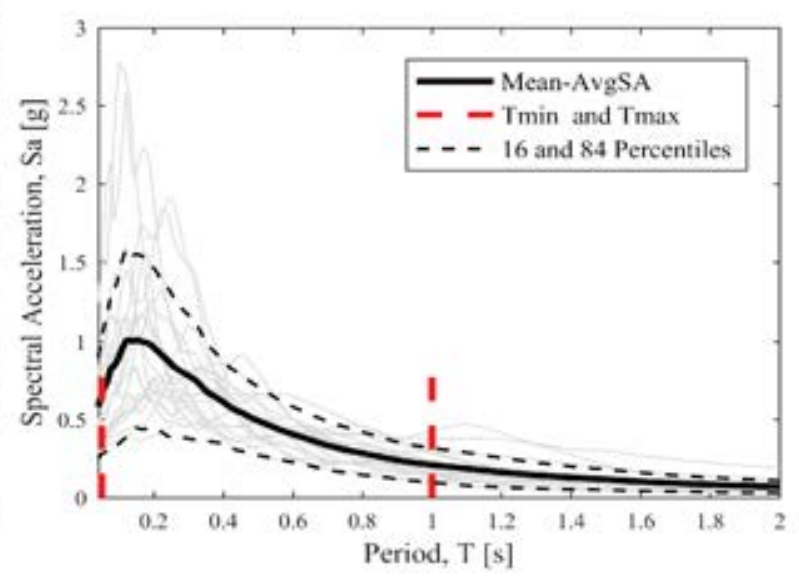

(b) Scheme of ground motion record selection

Figure 8: Hazard curves and ground motions selected using AvgSa for the site locations. 
Multiple-stripe analysis (MSA) [30] was conducted to characterize the response of the structures using the records selected. The results from the MSA were used to develop collapse fragility curves, for all models for both buildings, by recording at each intensity level, the number of collapses observed. The collapse criteria adopted here was based as the first of: the shear force demand exceeds the shear resistance of one or more of the flexural elements; the rotation of one or more flexural elements exceeds the SLC deformation limits; the shear deformation in one or more of the beam-column joints exceeds $0.02 \mathrm{rad}$ [19]. The curves were fitted from the MSA collapse data using a lognormal distribution and maximum-likelihood estimation [31]. The fragility curves obtained from the fitting procedure account for the recordto-record variability of the selected ground motions (Figure 9). To account for the modelling uncertainty, the median and dispersion values from the fitting procedure were modified following the recommendations of O'Reilly and Sullivan [19]. Moreover, Figure 9 also illustrates the expected economic losses, which were determined through the software PACT (version 3.1.2) [12].

The retrofitting alternatives A3 and A4 substantially reduce the collapse vulnerability and expected economic losses, especially for Building 1. A1 improves the collapse capacity of Building 1 and expected losses but this improvement is not as prominent as the one given by A3 and A4. On the other hand, A2 achieves a slight enhancement of both aspects. In case of Building 2, A4 has a considerably better performance in terms of collapse vulnerability and expected economic losses. On the other hand, A1 and A3 reach a similar reduction for both aspects, and lastly, A2 does not seem to improve these two parameters. Indeed, A2 has a worse performance compared to the as-built configuration of Building 2. Furthermore, from Figure $7 \mathrm{~b}$, it can be predicted that A2 would generate higher floor accelerations, as well as higher losses associated with this demand parameter. Likewise, the period shortening observed in Table 2 indicates that this strategy will be conditioned to larger inertial forces. As a result, the structural elements will be subjected to higher internal forces, which leads to more local failures. These same effects are expected for A3, however, the contribution of CFRP increases the local strength and thereby decreases the number of element failures (i.e. collapse cases).

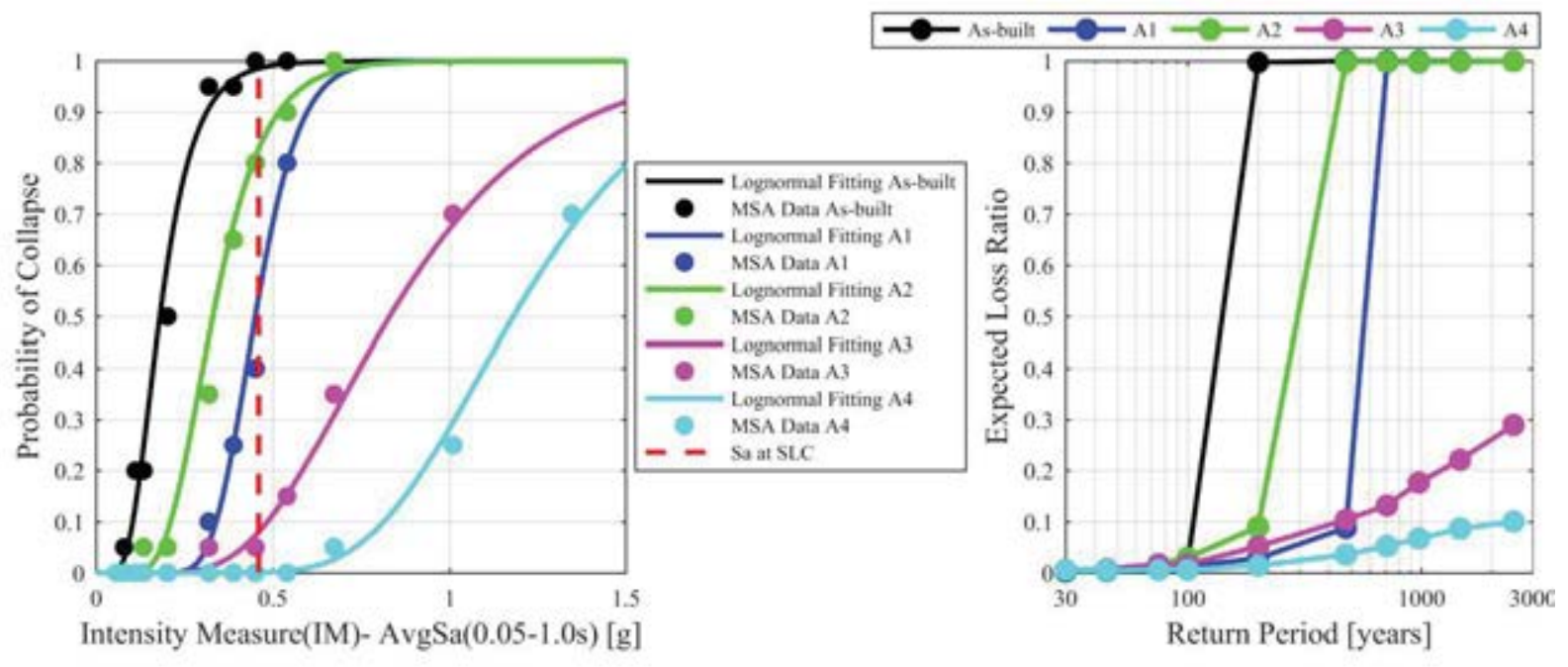

(a) Building 1 

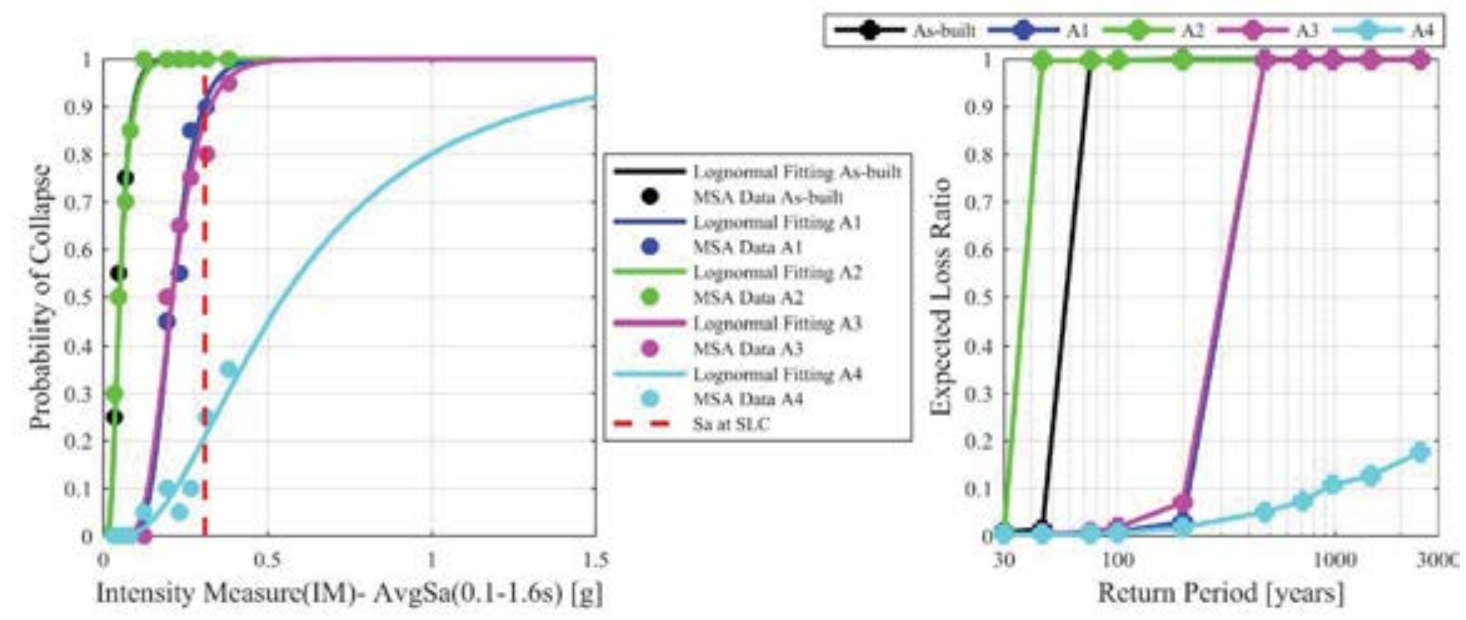

(a) Building 2

Figure 9: Collapse vulnerability and expected economic losses.

Tables 5 and 6 report the expected annual losses (EAL) and expected annual environmental impacts (EAEI) for all configurations of both buildings. These calculations were based on the total replacement cost of the buildings. The average costs of building demolition and reconstruction were assumed as $95.50 € / \mathrm{m}^{2}$ and $1805.75 € / \mathrm{m}^{2}$, respectively [32]. Given an approximate floor area of $1395 \mathrm{~m}^{2}$, the demolition and reconstruction costs were estimated to be $133,223 €$ and $2,519,021 €$ respectively (total replacement cost of 2,652,244€) for Building 1. On the other hand, for Building 2 with an approximate floor area of $2067 \mathrm{~m}^{2}$ the demolition and reconstruction cost resulted in 197,427€ and 3,733,027€, respectively (total replacement cost of 3,930,454€). Furthermore, replacement EI for Building 1 is 1,830,000kg-CO2e and $2,713,000 \mathrm{~kg}-\mathrm{CO} 2 \mathrm{e}$ for Building 2. For simplicity, the total replacement cost and EIs were considered to be the same for all of the alternatives in each building case.

\begin{tabular}{ccccc}
\hline Model & $\begin{array}{c}\text { EAL } \\
{[\%]}\end{array}$ & $\begin{array}{c}\text { Rep. } \\
\text { Cost[€] }\end{array}$ & $\begin{array}{c}\text { EAEI } \\
{[\%]}\end{array}$ & $\begin{array}{c}\text { Rep. EI } \\
{\left[\mathrm{kgCO}_{2} \mathrm{e}\right]}\end{array}$ \\
\hline As-built & 0.50 & $2,652,244$ & 0.51 & $1,830,000$ \\
A1 & 0.20 & & 0.18 & \\
A2 & 0.43 & & 0.39 & \\
A3 & 0.16 & & 0.11 & \\
A4 & 0.06 & & 0.04 & \\
\hline
\end{tabular}

Table 5: EAL and EIs expressed as a percentage (\%) of the estimated replacement cost and EI, Building 1.

\begin{tabular}{ccccc}
\hline \multirow{2}{*}{ Model } & $\begin{array}{c}\text { EAL } \\
{[\%]}\end{array}$ & $\begin{array}{c}\text { Rep. } \\
\text { Cost }[€]\end{array}$ & $\begin{array}{c}\text { EAEI } \\
{[\%]}\end{array}$ & $\begin{array}{c}\text { Rep. EI } \\
{\left[\mathrm{kgCO}_{2} \mathrm{e}\right]}\end{array}$ \\
\hline As-built & 1.46 & $3,930,454$ & 1.47 & $2,713,000$ \\
A1 & 0.33 & & 0.33 & \\
A2 & 1.77 & & 1.77 & \\
A3 & 0.38 & & 0.34 & \\
A4 & 0.13 & & 0.12 & \\
\hline
\end{tabular}

Table 6: EAL and EIs expressed as a percentage (\%) of the estimated replacement cost and EI, Building 2. 


\section{APPLICATION OF MCDM}

\subsection{Input variables}

The input variables (i.e. weight vector $\mathrm{w}$ and decision matrix D) are reported in Table 7 and 8 for Building 1 and 2, respectively. The values assigned to the decision matrix (D) were determined as described in Section 2.2 whereas the weight vector (w) was adopted from Carofilis et al. [11].

\begin{tabular}{lllllllll}
\hline $\begin{array}{l}\text { DV } \\
\text { [units] }\end{array}$ & $\begin{array}{l}\text { C1 } \\
{[€]}\end{array}$ & $\begin{array}{l}\text { C2 } \\
{[€]}\end{array}$ & $\begin{array}{l}\text { C3 } \\
{[\text { days }]}\end{array}$ & C4 & C5 & C6 & $\begin{array}{l}\text { C7 } \\
{[\%]}\end{array}$ & $\begin{array}{l}\text { C8 } \\
{[\%]}\end{array}$ \\
\hline A1 & 850,458 & $1,520,883$ & 36 & 0.07 & 0.25 & 1.40 & 0.20 & 0.18 \\
A2 & 43,120 & 229,829 & 8 & 0.17 & 0.04 & 14.70 & 0.43 & 0.39 \\
A3 & 389,477 & 794,218 & 28 & 0.28 & 0.25 & 14.80 & 0.16 & 0.11 \\
A4 & 679,445 & 810,781 & 29 & 0.49 & 0.45 & 1.20 & 0.06 & 0.04 \\
w & 6.83 & 7.04 & 6.17 & 5.38 & 5.54 & 6.50 & 6.87 & 6.08 \\
\hline
\end{tabular}

Table 7: Input variables for MCDM, Building 1.

\begin{tabular}{lllllllll}
\hline $\begin{array}{l}\text { DV } \\
\text { [units] }\end{array}$ & $\begin{array}{l}\text { C1 } \\
{[€]}\end{array}$ & $\begin{array}{l}\text { C2 } \\
{[€]}\end{array}$ & $\begin{array}{l}\text { C3 } \\
\text { [days] }\end{array}$ & C4 & C5 & C6 & $\begin{array}{l}\text { C7 } \\
{[\%]}\end{array}$ & $\begin{array}{l}\text { C8 } \\
{[\%]}\end{array}$ \\
\hline A1 & $1,792,080$ & $2,915,946$ & 92 & 0.07 & 0.25 & 1.33 & 0.33 & 0.33 \\
A2 & 41,528 & 43,487 & 16 & 0.17 & 0.04 & 2.90 & 1.77 & 1.77 \\
A3 & 151,435 & 254,743 & 25 & 0.28 & 0.25 & 2.90 & 0.38 & 0.34 \\
A4 & 224,661 & 186,082 & 28 & 0.49 & 0.45 & 1.24 & 0.13 & 0.12 \\
w & 6.83 & 7.04 & 6.17 & 5.38 & 5.54 & 6.50 & 6.87 & 6.08 \\
\hline
\end{tabular}

Table 8: Input variables for MCDM, Building 2.

\subsection{Ranking of retrofitting interventions}

The rank of each retrofitting alternative is listed in Table 9 (Building 1) and Table 10 (Building 2). To evaluate the influence of EI, two analyses were carried out, i.e. one including EIs (all DVs of Table 1) and other without considering EIs (excluding C8). For Building 1, it is observed that when EI is integrated into the MCDM, A4 results as the most convenient retrofit alternative. The relative closeness among A4, A3 and A2 is very similar, especially between $\mathrm{A} 3$ and A2. On the other hand, when EI is excluded from the analysis, A2 is ranked as the first option. In this scenario, the relative closeness of A2 is larger than A3 and A4, but for A3 and A4 this parameter is close to one another.

Moreover, for Building 2, the influence of EIs does not affect the rank preferences of the retrofitting options. For both analysis scenarios, A3 is selected as the most ideal solution with a considerably larger relative closeness compared to the other strategies. Indeed, the rank remains unchanged (i.e. A3-A4-A2-A1). However, it is observed that the relative closeness decreases when EIs are not considered in the MCDM analysis. A possible reason for this same pattern is that the values associated with EI (C8) for Building 2 are very similar to EAL (C7). Therefore, this similarity does not affect considerably the rank preference, especially since $\mathrm{C} 8$ 
is considered sixth in the order of preference of the weight vector w (i.e. sixth larger weight 6.08).

One could argue that A2 should not be considered within the set of retrofitting alternatives for both buildings, given that, even though the resulting lateral capacity is considerably larger than that of the as-built configuration and the storey drifts are reduced, the performance capacity (controlled by joint failure) remains unchanged. Additionally, the nonlinear dynamic analysis showed that the collapse vulnerability and expected losses were only slightly improved or even worsened with respect to the original building. However, this depends on the analysis and/or conditions of the project. Additionally, integration of refined methods or conservative assessment approaches that are more consistent with reality may not be possible, especially for regions where prompt solutions are needed. Therefore, the MCDM may be applied to select the most appropriate solution in conjunction with simplified methods, as long as they include relevant evaluation parameters for a particular case study.

\begin{tabular}{llllll}
\hline Consideration & Alternatives & A1 & A2 & A3 & A4 \\
\hline With EI & $\begin{array}{l}\text { Relative } \\
\text { closeness }\end{array}$ & 0.472 & 0.522 & 0.523 & $\mathbf{0 . 5 3 9}$ \\
\multirow{2}{*}{ No EI } & $\begin{array}{l}\text { Rank } \\
\text { Relative } \\
\text { closeness }\end{array}$ & IV & III & II & I \\
& Rank & IV & I & III & II \\
\hline
\end{tabular}

Table 9: Rank of alternatives for Building 1.

\begin{tabular}{llllll}
\hline Consideration & Alternatives & A1 & A2 & A3 & A4 \\
\hline With EI & $\begin{array}{l}\text { Relative } \\
\text { closeness }\end{array}$ & 0.444 & 0.577 & $\mathbf{0 . 7 5 6}$ & 0.697 \\
\multirow{2}{*}{ No EI } & $\begin{array}{l}\text { Rank } \\
\text { Relative } \\
\text { closeness }\end{array}$ & IV & III & I & II \\
& Rank & IV & III & I & II \\
\hline
\end{tabular}

Table 10: Rank of alternatives for Building 2.

\section{CONCLUSIONS}

This paper looked at the seismic retrofitting of two case-study existing buildings in Italy. Several retrofitting alternatives were examined and the choice via a multi-criteria decision making (MCDM) framework considering economic, social, environmental and technical aspects was evaluated. Based on the results obtained, the following observations can be made:

- The influence of environmental impacts greatly affects the preference of a retrofitting strategy and can alter the rank of the options in a multi-criteria decision making analysis, highlighting the importance of also considering the environmental impacts for evaluating retrofitting options;

- The retrofitting strategy based solely on CFRP was ranked as the least convenient solution in both buildings. Even though this strategy has the lowest architectural impact, the high 
values associated with installation cost, maintenance and duration of works, diminish its attractiveness;

- The strategy with steel braces and CFRP is considered as the most convenient strategy for Building 2 and second-best for Building 1; this strategy achieves a balance among all the evaluation parameters that make it stand out among the other strategies;

- The strategy involving CFRP and viscous dampers achieved the best structural performance and was selected as the most beneficial strategy for Building 1. However, this option was ranked as the second most favourable solution for Building 2;

- The retrofitting scheme composed only of exterior steel braces had an insignificant performance improvement, but its lowest implementation costs made it stand out as the most convenient strategy for Building 1 when environmental impacts were not considered. This strategy is however not practical for Building 2 since its performance resulted to be worse than that of the as-built configuration.

Lastly, MCDM can be adopted in large scale scenarios or in cases where there are limited resources (e.g. developing countries) where retrofitting options are evaluated for many buildings. In such cases, simplified methods [33] can be practical for selecting the most appropriate retrofitting strategy, as an alternative to refined nonlinear dynamics analysis.

\section{REFERENCES}

[1] D. Perrone, G.J. O'Reilly, R. Monteiro, A. Filiatrault. Assessing seismic risk in typical Italian school buildings: From in-situ survey to loss estimation. International Journal of Disaster Risk Reduction, 44, 101448, 2020, https://doi.org/10.1016/j.ijdrr.2019.101448.

[2] W. Carofilis, D. Perrone, G. O’Reilly, R. Monteiro, A. Filiatrault. Seismic retrofit of existing school buildings in Italy: performance evaluation and loss estimation.

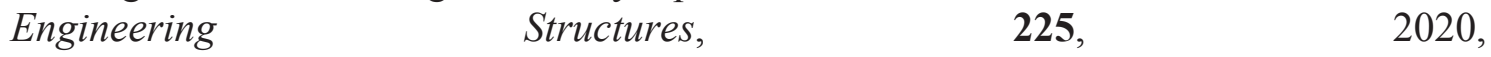
DOI: https://doi.org/10.1016/j.engstruct.2020.111243.

[3] L. Sousa, M. Monteiro. 2018. Seismic retrofit options for non-structural building partition walls: Impact on loss estimation and cost-benefit analysis. Engineering Structures, 161, 8-27, 2018, doi: 10.1016/j.engstruct.2018.01.028.

[4] W. Carofilis, G. Gabbianelli, R. Monteiro. Assessment of multi-criteria evaluation procedures for identification of optimal retrofitting strategies for existing RC buildings, Journal of Earthquake Engineering, 2021, DOI:10.1080/13632469.2021.1878074.

[5] Caterino N, Iervolino I, Manfredi G, Cosenza E. Multi-criteria decision making for seismic retrofitting of RC structures. Journal of Earthquake Engineering, 12, 555-583, 2008, DOI: 10.1080/13632460701572872.

[6] R. Gentile, C. Galasso, Simplified seismic loss assessment for optimal structural retrofit of RC buildings. Earthquake Spectra, 00, 1-20, 2020, DOI: 10.1177/8755293020952441.

[7] M. Caruso, R. Pinho, F. Bianchi, F. Cavalieri, M. Teresa. A Life Cycle Framework for the Identification of Optimal Building Renovation Strategies Considering Economic and Environmental Impacts. Sustainability, 26, 2020. 
[8] N. Clemett, W. Carofilis, G.J. O’Reilly, G. Gabbianelli, R. Monteiro. Optimal retrofitting of existing buildings considering environmental impact. Engineering Structures, Submitted - Unpubl n.d.

[9] T.L. Saaty. The Analytic Hierarchy Process McGraw-Hill. New York, 1980.

[10] C.L. Hwang, K. Yoon. Multiple Attribute Decision Making. Lecture Notes in Economics and Mathematical Systems, 186, 1981. Springer-Verlag. Berlin.

[11] W. Carofilis, N. Clemett, G. Gabbianelli, G. O’Reilly, R. Monteiro. Influence of parameter uncertainty in multi-criteria decision-making when identifying optimal retrofitting strategies for RC buildings. Journal of Earthquake Engineering, Submitted Unpubl n.d.

[12] FEMA. Seismic Performance Assessment of Buildings, Volume 3 - Supporting Electronic Materials and Background Documentation, Third Edition, 2018. Washington D.C.: Federal Emergency Management Agency.

[13] G. Majeau-Bettez, A.H. Strømman, E.G. Hertwich. Evaluation of Process- and InputOutput-based Life Cycle Inventory Data with Regard to Truncation and Aggregation Issues. Environ Sci Technol, 45, 10170-7, 2011, https://doi.org/10.1021/es201308x.

[14] W. Leontief. Input-Output Economics. Second, reprint. Oxford University Press; 1986.

[15] C.T. Hendrickson, A. Horvath, S. Joshi, M. Klausner, L.B. Lave, F.C. McMichael. Comparing two life cycle assessment approaches: a process model vs. economic inputoutput-based assessment. Proc. 1997 IEEE Int. Symp. Electron. Environ. ISEE-1997, San Francisco, CA, USA: IEEE; 176-81, 1997. https://doi.org/10.1109/ISEE.1997.605313.

[16] M. Huang, K. Simonen. Comparative Environmental Analysis of Seismic Damage in Buildings. J Struct Eng, 146, 05019002, 2020. https://doi.org/10.1061/(ASCE)ST.1943$\underline{541 X .0002481 .}$.

[17] Y. Yang, W.W. Ingwersen, T.R. Hawkins, M. Srocka, D.E. Meyer. USEEIO: A new and transparent United States environmentally-extended input-output model. J Clean Prod, 158, 308-18, 2017, https://doi.org/10.1016/j.jclepro.2017.04.150.

[18] F. McKenna, M.H. Scott, G.L. Fenves. Nonlinear finite-element analysis software architecture using object composition. J Comput Civ Eng, 24, 95-107, 2010, doi: 10.1061/ (ASCE) CP.1943-5487.0000002.

[19] G.J. O'Reilly, T.J. Sullivan. Modeling Techniques for the Seismic Assessment of the Existing Italian RC Frame Structures. Journal of Earthquake Engineering, 23(8), 12621296, 2019, DOI: 10.1080/13632469.2017.1360224.

[20] M.H. Scott, G.L. Fenves. Plastic hinge integration methods for force-based beam column elements. J Struct Eng, 132, 244-52, 2006, doi: 10.1061/ (ASCE)0733-9445(2006) 132:2(244).

[21] Norme Tecniche Per Le Costruzioni (NTC). Rome, Italy, 2018.

[22] K. Sassun, T.J. Sullivan, P. Morandi, D. Cardone. Characterising the in-plane seismic performance of infill masonry. Bull $N$ Z Soc Earthq Eng, 49, 98-115, 2016, https://doi.org/10.5459/bnzsee.49.1.98-115. 
[23] L.D. Decanini, L. Liberatore, F. Mollaioli. Strength and stiffness reduction factors for infilled frames with openings. Earthq Eng Eng Vib, 13, 437-54, 2014, https://doi.org/10.1007/s11803-014-0254-9.

[24] G.J. O'Reilly (2021). Limitations of Sa(T1) as an intensity measure when assessing nonductile infilled RC frame structures. Bulletin of Earthquake Engineering. https://doi.org/10.1007/s10518-021-01071-7

[25] Global Earthquake Model (GEM). The openquake-engine user manual. Open- Quake Manual for Engine version 3.7.0, 2019, 183. 10.13117/GEM.OPENQUAKE.MAN.ENGINE.3.7.0

[26] C. Meletti, F. Galadini, G. Valensise, M. Stucchi, R. Basili, S. Barba, G. Vannucci, E. Boschi. A seismic source zone model for the seismic hazard assessment of the Italian territory. Tectonophysics, 450 (1-4), 85-108, 2008, doi: 10.1016/j. tecto.2008.01.003.

[27] S. Akkar, M.A. Sandikkaya, J.J. Bommer. Empirical ground-motion models for pointand extended-source crustal earthquake scenarios in Europe and the Middle East. Earthquake Engineering, 12, 359-387, 2014, doi:10.1007/ s10518-013-9461-4.

[28] M. Sandikkaya, S. Akkar, P. Bard. A nonlinear site-amplification model for the next PanEuropean ground-motion predictions equations. Bulletin of the Seismology Society of America, 130 (1): 1-32, 2013, doi: 10.1785/ 0120120008.

[29] M. Kohrangi, P. Bazzurro, D. Vamvatsikos, A. Spillatura. Conditional spectrum-based ground motion record selection using average spectral acceleration. Earthquake Engineering \& Structural Dynamics, 46 (10), 1667-85, 2017, doi: 10.1002/eqe.2876

[30] K.R. Mackie, B. Stojadinović. Comparison of Incremental Dynamic, Cloud, and Stripe Methods for Computing Probabilistic Seismic Demand Models. Struct. Congr. 2005, New York, New York, United States: American Society of Civil Engineers, 1-11, 2005, https://doi.org/10.1061/40753(171)184.

[31] J.W. Baker. Efficient Analytical Fragility Function Fitting Using Dynamic Structural Analysis. Earthq Spectra, 31, 579-99, 2015, https://doi.org/10.1193/021113EQS025M.

[32] G. O'Reilly, D. Perrone, M. Fox, R. Monteiro, A. Filiatrault. Seismic assessment and loss estimation of existing school buildings in Italy. Eng Strt, 168,142-62, 2018, https://doi.org/10.1016/j.engstruct.2018.04.056.

[33] S. Ruggieri, D. Perrone, M. Leone, G. Uva, M.A. Aiello. A prioritization RVS methodology for the seismic risk assessment of RC school buildings. International Journal of Disaster Risk Reduction, 51, 101807, 2020, https://doi.org/10.1016/j.ijdrr.2020.101807. 